JOURNAL DE PHYSIQUE IV

Colloque C2, supplément au Journal de Physique III, Volume 5, février 1995

\title{
Precipitation and Shape Recovery in CuAlNi+TiB Alloy
}

\author{
H. Morawiec and M. Gigla \\ Institute of Physics and Chemistry of Metals, University of Silesia, 40-007 Katowice, Bankowa 12, \\ Poland
}

\begin{abstract}
The ageing process in the $\mathrm{CuAlNi}+\mathrm{TiB}$ alloy may be performed as a three stage process. The first stage causes a decrease in characteristic temperatures of transformation, in hardness and electrical resistivity. It is probably due to annealing out of vacancies of the alloy as well as to ordering process. The second and third stages were identified as connected with the coherent and noncoherent precipitation of $\gamma_{2}$ particles. The change of shape recovery temperature in the second stage was expressed as a function of time and temperature of ageing.
\end{abstract}

\section{INTRODUCTION}

It is well know that ageing shifts the characteristic transformation temperatures, changes the structure of the martensite as well as the mechanical properties, therefore this process is of great interest.

The results and the interpretation of $\beta$-phase ageing is still controversial. Basing on changes in the characteristic temperatures caused by an isothermal ageing process one can suppose that this process is performed in one, two or even three stages. The continuous increase in all the transformation temperatures with ageing time was explained by solute depletion of the matrix due to precipitation of the $\gamma_{2}$ particle phase [1]. In the case of two observed stages, the first was interpreted as caused by atomic ordering [2-5] or coherent precipitation [3]. The second stage is explained by noncoherent precipitation [2-5]. Three stages of the kinetic during isothermal ageing were stated in [6]. The first and second stages are attributed to short range phenomena like $\mathrm{DO}_{3}$ ordering and beginning of spinodal decomposition. The second stage may be also the beginning of the precipitation. During the third stage equilibrium phases precipitation phenomena occur. These differences in the ageing process may be explained not only by the varying chemical compositions of the studied alloys $[4,5]$ but also by the presence of the refining elements $[2,3]$.

The aim of this paper was to prove the feasibility of describing the shape recovery temperature as a function of ageing parameters assuming the continuous increase of hardness and $A_{s}$ temperature for the same stages of ageing process.

\section{EXPERIMENTAL}

Studies were carried out on an alloy with the following chemical composition: $82.68 \% \mathrm{Cu}-13.42 \% \mathrm{Al}$ $3.1 \% \mathrm{Ni}-0.25 \% \mathrm{Ti}-0.063 \% \mathrm{~B}$ (by weight). The strips were prepared by hot rolling.

Samples in the form of $1.0 \mathrm{~mm}$ thick strips were quenched in water from $850^{\circ} \mathrm{C}$ and next aged at temperatures $80^{\circ} \mathrm{C}, 120^{\circ} \mathrm{C}, 160^{\circ} \mathrm{C}$ and $200^{\circ} \mathrm{C}$ for times from 0.25 hour to 312 hours. The shape recovery 
test was carried out by bending the samples around a cylinder of $90^{\circ}$ and measuring the change of angle due to reheating. Hardness was measured by the Vickers test and the characteristic temperatures from the DTA method using the Mettler instrument. The structure studies and identification of the precipitates were carried out using the analitical Philips electron microscope.

\section{EXPERIMENTAL RESULTS}

Microscope examination of the quenched alloy showed that the dominating phase is martensite of $2 \mathrm{H}$ type structure exhibiting large number of defects. Also identified in the alloy were numerous primary precipitates found to be $\mathrm{TiB}_{2}$.
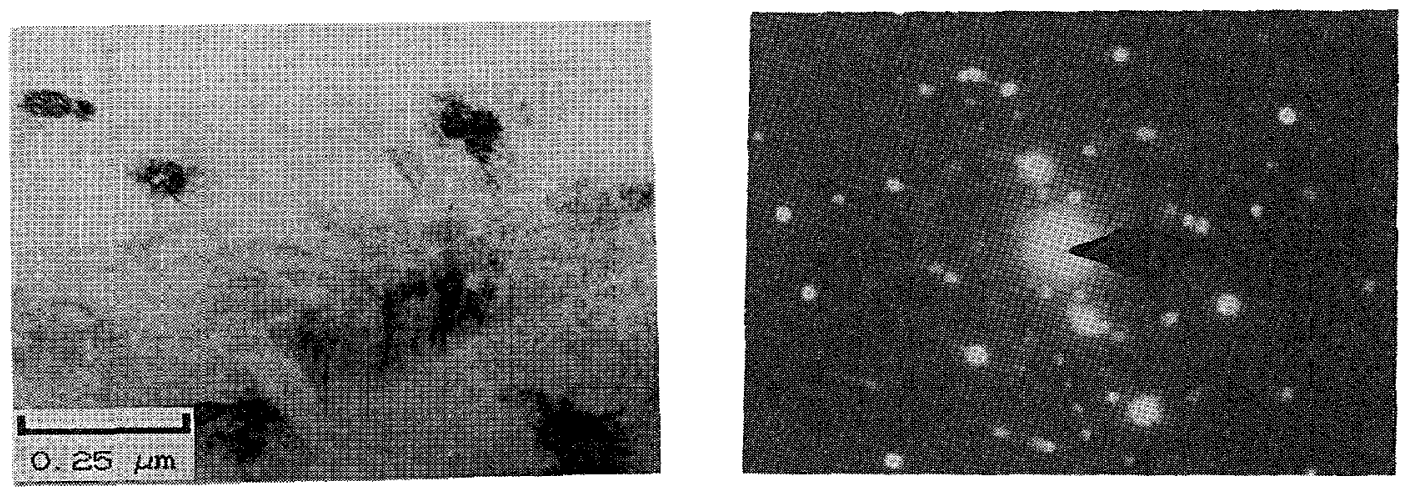

Fig. 1 Coherent particles of $\gamma_{2}$ phase in the alloy aged at $200^{\circ} \mathrm{C}$ for 2 hours and corresponding diffraction pattern

After short ageing times at $200^{\circ} \mathrm{C}$ coherent particles appear as secondary precipitates (Fig.1) which by using the microbeam diffraction were identified as $\gamma_{2}$-phase. The chemical compostion of these precipitates was determined by means of the EDS - method in the microscope and it was as follows: Cu20.8 wt. \% Al-5.3wt. \% Ni-0.2wt. \% Ti. This composition is in agreement with that established by [7]. Extending the ageing time at the same temperature the increase in size of these particles and the loss of the coherency is observed (Fig.2).
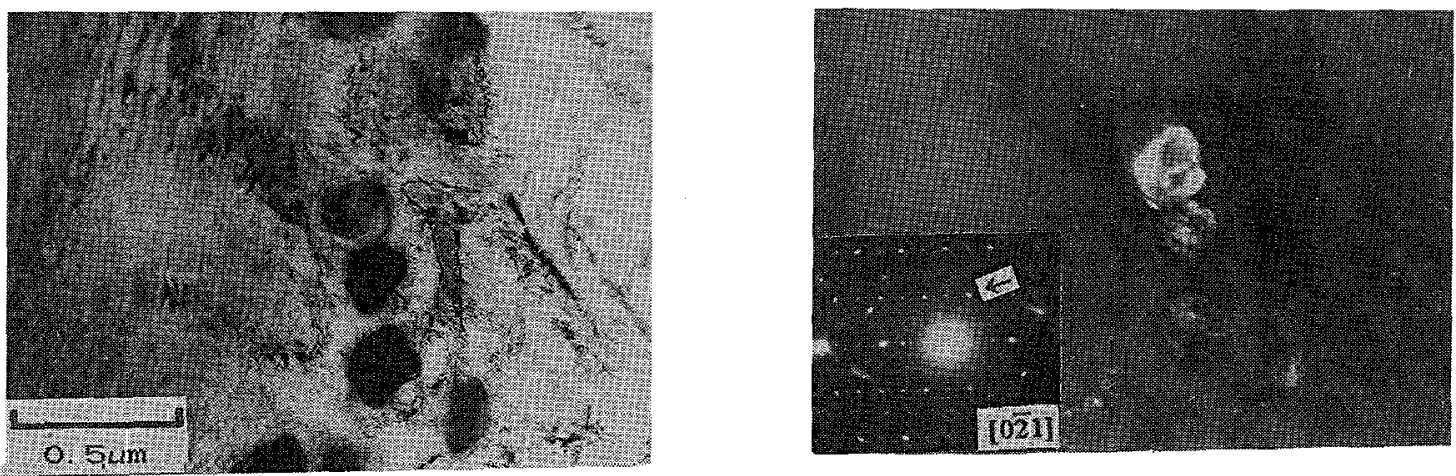

Fig. 2 Noncoherent particles of $\gamma_{2}$ phase in the alloy aged at $200^{\circ} \mathrm{C}$ for 66 hours

The shape recovery temperature versus ageing time is shown on Fig.3. As compared with the quenched state for the shortest ageing time $t=0,25 \mathrm{~h}$ and $\mathrm{t}=0,5 \mathrm{~h}$ the shape recovery temperature decreased but for longer ageing time a marked increase in temperatures of shape recovery with increase of ageing time can be seen. In order to describe this curve by least square method it was necessary to approximate the 


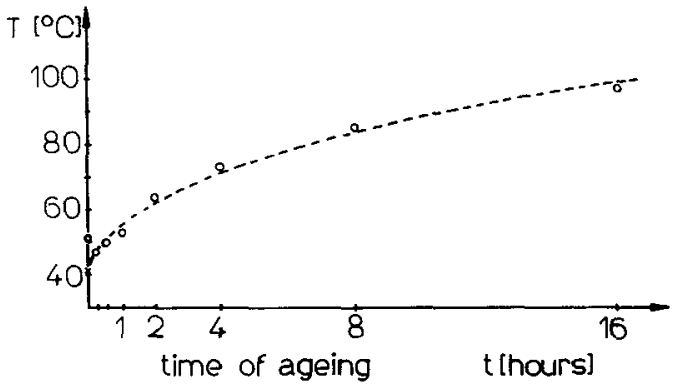

Fig. 3 The shape recovery temperature versus ageing time

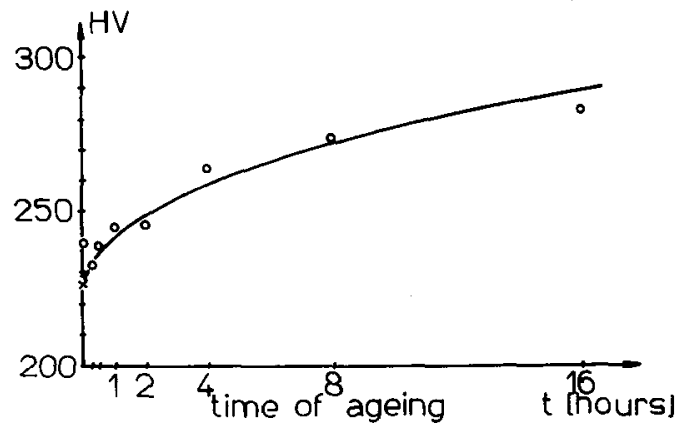

Fig. 5 Hardness of the alloy versus time of ageing

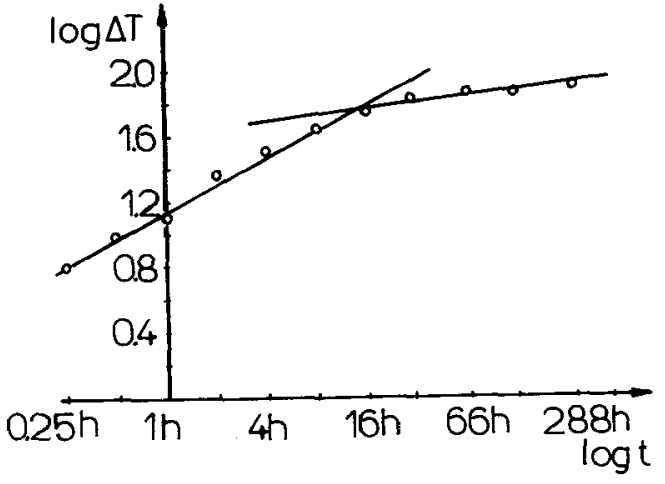

Fig. 4 Logarythm of the normalized recovery temperature versus logarythm of ageing time

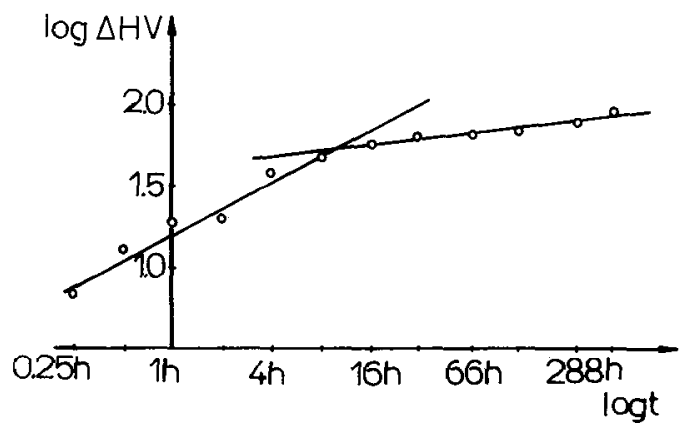

Fig. 6 Logarythm of the normalized hardness versus logarythm of ageing time

curve to time ageing equal zero. This allowed to determine the reference point $T_{R}$ to which the relation of shape recovery temperature increase $\Delta \mathrm{T}=\mathrm{T}-\mathrm{T}_{\mathrm{R}}$ was counted apart from the decrease of this temperature (first stage on this curve) caused by the annealing out of vacancies. After fitting the curve to the test points: $T=15.04 t^{0.5}+40.5$ the temperature reference point was obtained $T_{R}=40.5^{\circ} \mathrm{C}$. The obtained relationship $\log \Delta \mathrm{T}=\mathrm{f}(\log \mathrm{t})$ (Fig.4) shows two further stages of ageing which caused increase in shape recovery temperature. The first one may be described by

$$
\Delta \mathrm{T}=\mathrm{A}_{1} \mathrm{t}^{\mathrm{0} .5 \mathrm{~h}} \text {. }
$$

and the other by $\Delta T=A_{2} t^{0.12}$. Similar results were obtained for hardness measurements. Ageing for $\mathrm{t}=0.25 \mathrm{~h}$ and $\mathrm{t}=0.5 \mathrm{~h}$ at $\mathrm{T}=200^{\circ} \mathrm{C}$ causes lowering of hardness relating to the quenched state and increase for longer ageing time as shown on Fig. 5.

The same procedure as for shape recovery temperature allowed to obtain the relation of $\log \Delta H V$ versus $\log t$ (Fig.6). Again except for softening of specimens aged for shortest time two further stages of hardening caused by the ageing may be seen.

From Fig. 6 the one stage for shorter ageing times (up to 20 hours) may be expressed by

and the other by $\Delta \mathrm{H}=\mathrm{B}_{2} \mathrm{t}^{0.13}$.

$$
\Delta \mathrm{H}=\mathrm{B}_{1} \mathrm{t}^{0.49}
$$


Almost the same relations were obtained for the characteristic transformation temperatures as shown on Fig. 7.

\section{DISCUSSION}

The ageing process in the studied alloy occurs to be a three stage process. The first stage causes the lowering of transformation temperatures, hardness and electrical resistivity and hence may be interpreted as a superposition of vacancies annealing out and increase of the parent phase order. From the electron microscope observations and increase in hardness and electrical resistivity the second stage was identified as a coherent precipitation process of $\gamma_{2}$ particles, while at the third stage of ageing noncoherent $\gamma_{2}$ particles were identified. It is clear that the experimental hardness curve described by the least square

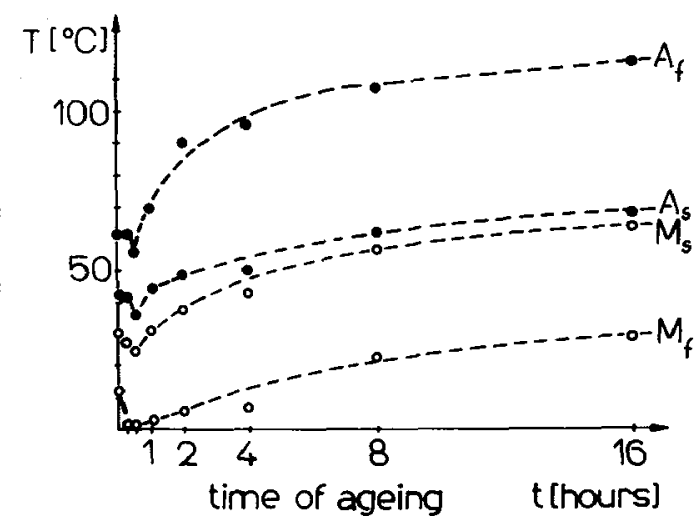

Fig. 7 The characteristic temperatures of the alloy versus ageing time method - equation (2) is in agreement with equation (1) describing the shape recovery temperature $\Delta \mathrm{T}$.

To confirm the hypothesis of the dominating influence of coherent precipitates on shifts in the temperatures of shape recovery $\Delta \mathrm{T}$, it would be necessary to obtain a similar relation as a function of ageing temperature. For this purpose the formula (1) could be corrected with respect to the change of the diffusion coefficient with the temperature:

where $\mathrm{E}$ - the activation energy

$$
\mathrm{D}=\mathrm{D}_{\mathrm{o}} \exp [-\mathrm{E} / \mathrm{kT}]
$$

$\mathbf{k}$ - the Boltzmann constant.

The change of shape recovery temperature $\Delta T$ as a function of ageing temperature confirmed this supposition. In this case again very good agreement was found between the curve describing the equation $\Delta T=f(T)$ as a function of ageing tempetature, and experimental data. The final equation expressing the relation between shifting of the shape recovery temperature and ageing time and temperature, has the form:

$$
\Delta \mathrm{T}=\mathrm{A}_{2} \mathrm{t}^{1 / 2} \exp [-\mathrm{B} / \mathrm{T}]
$$

After calculating the constants, this formula makes it possible to determine the changes in temperature of shape recovery as a function of time and temperature of ageing.

\section{CONCLUSIONS}

- The ageing process of the studied alloy consists of three stages.

- Ageing of this alloy in the stage of coherent precipitation causes hardening and increase in temperature of the shape recovery process.

- Increase of shape recovery temperature can be precisely described by temperature and time of the ageing process, hence by means of the ageing parameters it is possible to control the shape recovery temperature.

\section{REFERENCES}

[1] Fisher P., Dunne D., Kennon N., Proc. ICOMAT,(1986) p.946

[2] Morris M., Acta Metall. Mater. 40 (1992) 1573

[3] Hornbogen E., Kobus E., Z.Metallkde. 83 (1992) 105

[4] Tadaki T., Shimizu K., Proc MRS Int. Meeting Adv. Mater. 9 (1989) 291 
[5] Itsumi Y., Miyamoto Y., Takashima T., Kamei K., Sugimoto K., Mater. Sci. Forum $56-58$ (1990) 468

[6] Rodríguez P., Guénin G., Proc. The Martensite Transformation in Science and Technology, ed. by Hornbogen E., Jost N., Bochum (1989) p. 149

[7] Zhang Y., et al J.Phys. Condens. Matter. 5 (1992) 279

\section{ACKNOWLEDGMENTS}

This work was sponsored by the National Committee of Research through grant No 336429102 . 